\title{
Characterization of biochars produced from pyrolysis of pelletized agricultural residues.
}

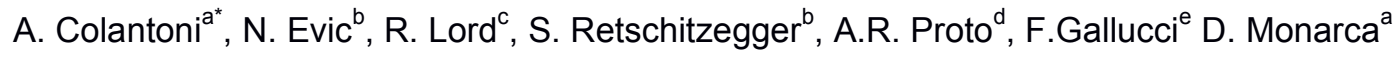 \\ a University of Tuscia, Department of science and technology for Agriculture, Forests, Nature and Energy, Italy \\ ${ }^{b}$ BIOENERGY 2020+ GmbH, Inffeldgasse 21b, 8010 Graz, Austria \\ ${ }^{c}$ University of Strathclyde, Department of Civil \& Environmental Engineering, Glasgow, United Kingdom \\ ${ }^{a}$ Università degli Studi di Reggio Calabria, Department of Agriculture, Reggio Calabria, Italy \\ ${ }^{e}$ Consiglio per la ricerca in agricoltura e l'analisi dell'economia agraria (CREA) Unità di ricerca per l'ingegneria Agraria, Via della \\ Pascolare 16, Monterotondo, Roma, Italy \\ * Corresponding author. Tel. +390761 357356; \\ Postal address: Via S. Camillo De Lellis, snc, Viterbo, Italy \\ E-mail address: colantoni@unitus.it
}

\section{Abstract}

Biochars produced from pelletized grape vine (GV) and sunflower husk (SFH) agricultural residues were studied by pyrolysis in a batch reactor at 400 and $500^{\circ} \mathrm{C}$. Chemical and physical evolution of the biomass under pyrolysis conditions was determined and the products were characterized, including the main gaseous organic components. . Results showed a decrease in solid biochar yield with increasing temperature. Biochar is defined as a "porous carbonaceous solid" produced by thermochemical conversion of organic materials in an oxygen depleted atmosphere, which has physiochemical properties suitable for the safe and long-term storage of carbon in the environment and, potentially, soil improvement. The aim of this work is to improve the knowledge and acceptability of alternative use of the biochar gained from agro-forestry biomass residuals, such as grape vine and sunflower husks, by means of modern chemical and physical characterization tools.

Keywords: biochar characterization, pyrolysis process, agricultural residues, biomass

\section{Introduction}

Agricultural wastes such as biomass residues are increasingly being recognized as valuable renewable feedstocks because of their carbon-rich composition [1]. In Austria, crop residues are used both to increase organic carbon content in top-soil [2] and for production of biofuels [3]. Pyrolysis, which is one of the most widely used thermo-chemical conversion technologies, refers to the thermal decomposition of organic components in biomass in an inert gas atmosphere, at medium temperature, for the production of biochar and condensable and non-condensable components (including water, highly oxygenated bio-oil, and synthesized gas) [4]. Biochar is the porous carbonaceous solid product of pyrolysis or incomplete combustion of organic materials [5], is similar to charcoal but is exclusively where its production is intended for agricultural and biological activities [6][7] and/or environmental applications [8]. Pyrolysis depolymerizes dry ligno-cellulosic feedstocks under an oxygen free environment. When the pyrolysis temperature is moderately high $\left(450-550^{\circ} \mathrm{C}\right)$, the volatiles arising from the pyrolysis process can be condensed to become a liquid product, called pyrolysis oil [9]. 
The potential benefits for the environment are the reduction of $\mathrm{CO}_{2}$ emissions and sequestration of carbon, and for the farmers additional income through energy production, solid renewable fuels or the production of adsorbents [10][11][12]. Pyrolysis temperature greatly affects the biochar characteristics in relation to its elemental composition and surface chemistry: biochars produced at low temperature have lower values of $\mathrm{pH}$ and may be suitable for improving the fertility of high $\mathrm{pH}$ soils [13] in arid regions [14]. During pyrolysis the feedstocks are degraded at temperatures between $350-1000{ }^{\circ} \mathrm{C}$ [15]; The temperature at which the biochar is produced has a significant effect on its physico-chemical properties [16]. The loss of mass of the starting product depends on the temperature and duration of the pyrolysis process. Generally, the char yield decreases at high temperatures [17]. This work is the outcome of a collaboration between the University of Tuscia, Bioenergy 2020+ (Graz) and Graz University of Technology funded through the BRISK project (www.briskeu.com). . The objective was to improve knowledge of the alternative uses of biochar gained from agro-forestry biomass residuals through chemical-physical characterizations, including the effect of the pyrolysis parameters on the properties of products..

\section{Materials and methods}

\subsection{Feedstock preparation}

Two biomass materials, including sunflower husk (Helianthus annuus L.) pellets (SFH) and grape vine (Vitis vinifera L.) pellets (GV), were used as a feedstock for biochar production. The pellets, $4 \mathrm{~mm}$ in diameter, were obtained from two common residual biomass sources in Austria. The materials were subjected to an ultimate chemical analysis before and after the pyrolysis experiments (Fig. 1) in order to obtain detailed information about the composition of biochar produced and the release of inorganic species from the fuel to the gas phase.
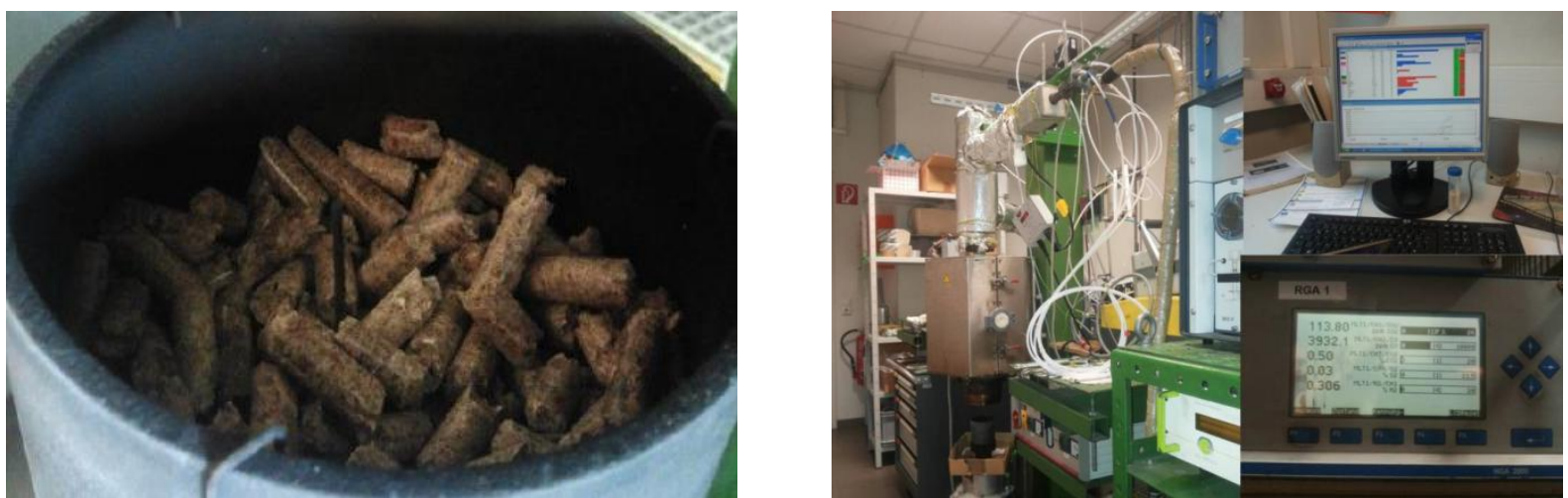

Fig. 1. Sample holder with Biomass inserted in the reactor (left); Labr eactor setup (right)

\subsection{Product characterization}

Characterization of biomass and biochar in terms of the $\mathrm{C}, \mathrm{H}$, and $\mathrm{N}$ contents was done in accordance with the standard EN 15104 by combustion and subsequent gas-phase chromatographic separation and measurement in an elemental analyzer. Cl content was determined according to EN 15289, using a digestion step based on bomb combustion in oxygen and absorption in $\mathrm{NaOH}(0.05 \mathrm{M})$, followed by 
measurement by ion chromatography. For the determination of the contents of major and minor ash forming elements (excluding $\mathrm{Cl}$ ), a multi-step pressurized digestion with $\mathrm{HNO}_{3}(65 \%) / \mathrm{HF}(40 \%) / \mathrm{H}_{3} \mathrm{BO}_{3}$ followed by measurement by inductively coupled plasma-optical emission spectroscopy (ICP-OES) or inductively coupled plasma-mass spectroscopy (ICP-MS) was applied, depending upon detection limits required. For total organic carbon (TC) analyses, an aliquot is treated with acid and the generated $\mathrm{CO}_{2}$ was measured by infrared (IR). The $\mathrm{Cl}$ content of ashes was measured by ion chromatography after elution for $24 \mathrm{~h}$ with deionized water.

\subsection{Batch pyrolysis tests}

Pyrolysis runs were performed at temperatures of 400 and $500^{\circ} \mathrm{C}$ for each sample (Table 1). The core of the reactor used in the experimental tests (Bioenergy 2020+ and Graz University of Technology) is a cylindrical retort (height, $35 \mathrm{~cm}$; inner diameter, $12 \mathrm{~cm}$ ), which is heated electrically and controlled by two separated proportional integral derivative (PID) controllers (Fig. 2). The reactor used has been especially developed for the investigation of fuel decomposition under fixed bed conditions. . The fuel (100 to $400 \mathrm{~g}$ depending on the fuel density) is put in a cylindrical holder measuring $100 \mathrm{~mm}$ in height and $95 \mathrm{~mm}$ in inner diameter. Both parts are made of fibre-reinforced SiC ceramics. Air, as well as different gas mixtures, can be applied as reaction media.

The sample is introduced into the pre-heated reactor so rapid heating can be achieved, comparable with that in real thermal conversion processes. The sample holder is equipped with five thermocouples to monitor the fuel bed temperatures during the test run (Fig. 2).

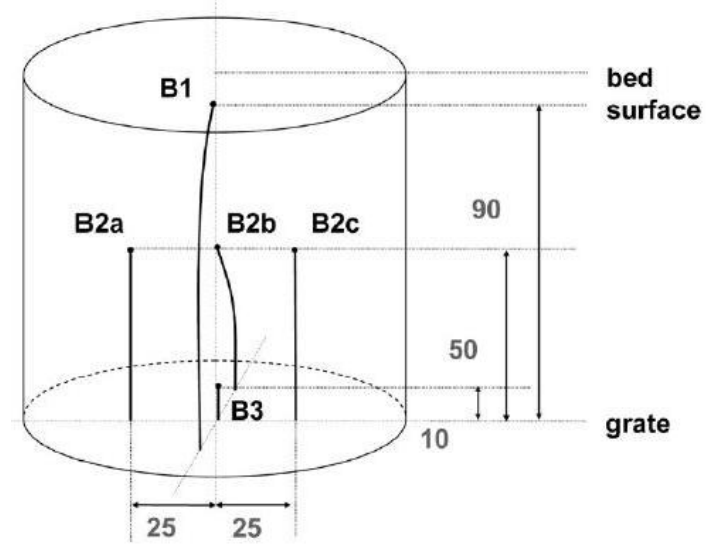

Fig. 2 Position of thermocouples in biomass bed

The sample holder and the sample are placed on the plate of a scale. The scale is mechanically separated from the retort by a liquid sealing.. With this setup it is possible to continuously measure the mass reduction of the sample during the pyrolysis/combustion process. To create an inert gas atmosphere and avoid the presence of oxygen inside the reactor a flow of nitrogen is applied. Flue gas samples are extracted from the gas volume above the fuel bed, treated and conditioned (dilution and temperature stabilization), and introduced into the gas analysis systems used in this study: (i) A Fourier transform infrared spectroscopy (FTIR) (Ansyco), to measure $\mathrm{CO}_{2}, \mathrm{H}_{2} \mathrm{O}, \mathrm{CO}, \mathrm{CH}_{4}, \mathrm{NO}, \mathrm{NH}_{3}, \mathrm{HCN}, \mathrm{NO}_{2}, \mathrm{~N} 2 \mathrm{O}$, light hydrocarbons and light condensable species; (ii) An Emerson NGA 2000; with paramagnetic-based measurement of $\mathrm{O}_{2}$; non dispersive infrared analysis (NDIR) of $\mathrm{CO}_{2}$ and $\mathrm{CO}$; and a heat conductivity 
sensor for $\mathrm{H}_{2}$.

The basic principle of this design is to provide a lab-scale batch reactor which is capable of simulating the fuel decomposition behaviour in real-scale fixed-bed thermal biomass conversion systems. Therefore, the following constraints were met: (i) an appropriate sample intake to consider secondary reactions in the fuel bed, (ii) high heating rates of the fuel comparable to real scale grate furnaces, (iii) inert reactor material to avoid reactions of the gases with the reactor, (iv) high flexibility regarding analytical equipment connected to the reactor, and $(\mathrm{v})$ online recording of relevant operational data and emissions, as well as the mass loss. The testing protocol was as follows: (i) Before the test run, the fuel is pre-dried to $10 \mathrm{wt} \%$ wet basis (wb) moisture content and a sub-sample of the fuel is submitted for wet chemical analyses. (ii) The fuel is added to the sample holder and lightly compressed to gain a packed bed with a realistic density. (iii) Then the reactor is preheated, with upper and lower heating element settings of 200 and $600 / 650{ }^{\circ} \mathrm{C}$, which are kept constant during the whole test run. (iv). Thereafter the sample holder with the fuel is introduced into the reactor, and the inert gas flow through the grate and the fuel bed is activated. All experiments documented in this paper have been performed with $N_{2}$ as the inert gas at a flow of around $3 L_{N} / \mathrm{min}$. (v) All parameters mentioned above are continuously recorded at $2 \mathrm{~s}$ intervals over the whole test run, which usually lasts between 30 and 60 min depending on the fuel mass applied. (vi) At the end of the test run the residues (biochar) are first visually evaluated and then removed and forwarded for chemical analysis. The schematic resume of the experimental setup is given in Fig. 3 .

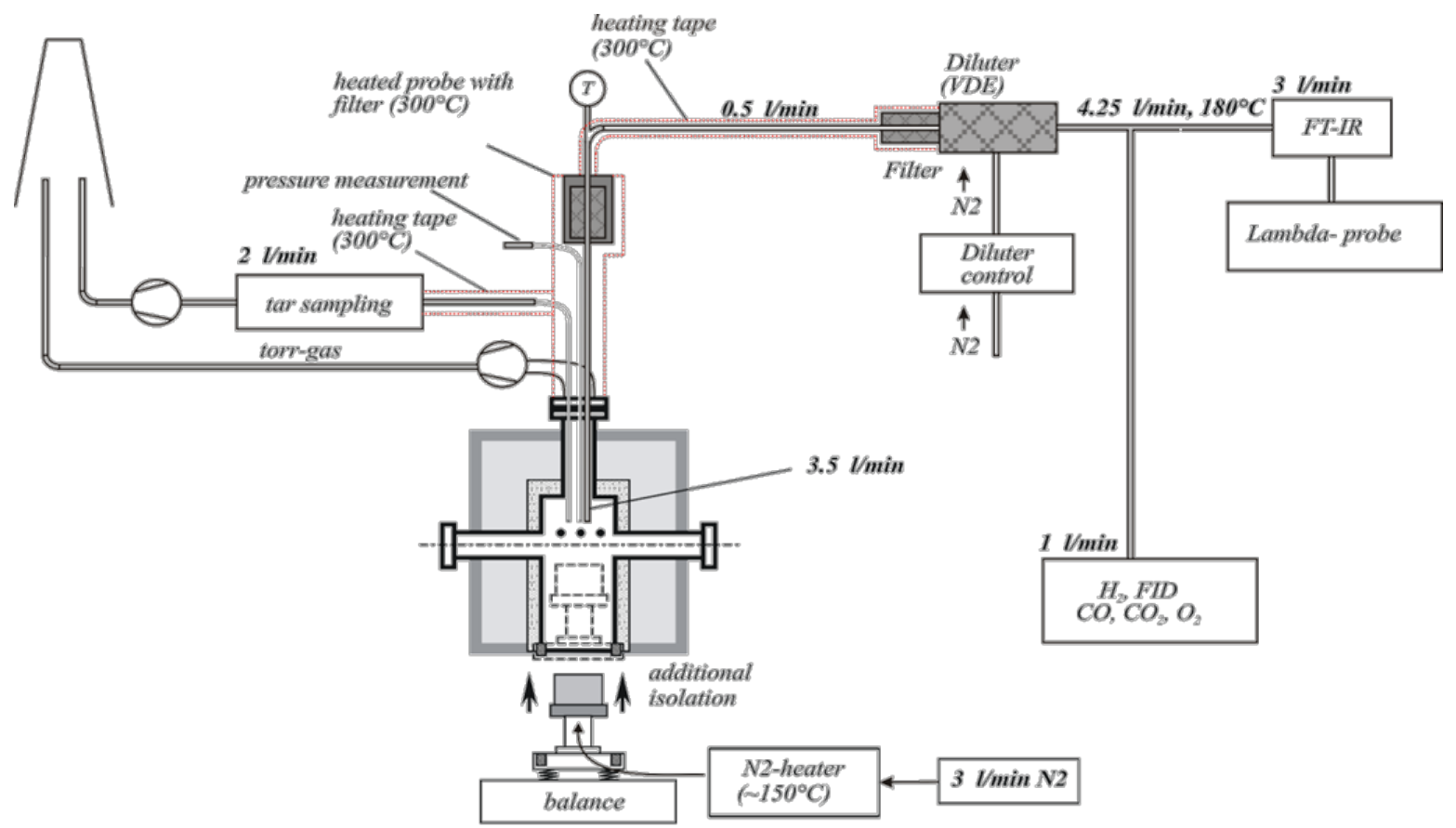

Fig. 3. Scheme of the lab-scale reactor setup used for pyrolysis test runs.

Table 1

Sample codes to each tests.

\begin{tabular}{cccc}
\hline Test No. & Sample name short & Sample name long & Temperature of pyrolysis $\left({ }^{\circ} \mathrm{C}\right)$ \\
\hline 1 & SFH & Sun flower husk pellet & 400 \\
2 & & & 500 \\
3 & GV & Grape vine pellet & 400 \\
4 & & & 500 \\
\hline
\end{tabular}




\section{Results and discussions}

\subsection{Biochar analysis}

Reactor temperature had a significant effect on the biochar's physico-chemical properties (Table 2). The yield of biochar decreased as pyrolysis temperature increased because the amount of gasification rises; a relatively low value of yield (below or slightly above $40 \%$ ) occurred at $400^{\circ} \mathrm{C}$ and $500^{\circ} \mathrm{C}$, agreeing with the observation of Zhang et al. [18]. The data showed that in biochar pyrolyzed at $400^{\circ} \mathrm{C}$, carbon content was about $70 \%$, hydrogen content just over $4 \%$, oxygen content ranging from $24 \%$ to $25 \%$, nitrogen about $1 \%$ and the sulfur content could be considered negligible, similar to the results obtained from Mimmo et al. [19]. Increasing the biochar production temperature resulted in an increase of over $3 \%$ in carbon and a decrease of about $2,5 \%$ in oxygen and $1 \%$ in hydrogen; more significant changes were observed in other studies at higher temperatures [20]. In comparison with the original biomas feedstock the biochar exhibits enhanced carbon concentrations (Fig. 5). The ash content moderately increases with increasing temperature and it was a little higher in the SFH than in the GV feedstock. The content of minor chemical elements was evaluated for each feedstock sample, as well as for the corresponding biochars obtained at $400^{\circ} \mathrm{C}$ (biochar-400) or $500^{\circ} \mathrm{C}$ (biochar-500) as presented in Table 3. An increase in concentration of most elements occurred after pyrolysis. It can be seen that pyrolysis strongly influences the concentrations of two potential major fertilizer elements, phosphorus and potassium, where a substantial increase could be observed in biochar. In SFH the potassium concentration increased from 8.070 to 20.200 (bichar-400) or 26.500 (biochar-500) mg/kg and in GV from 3.440 to 8.590 or $10.100 \mathrm{mg} / \mathrm{kg}$. The phosphorus content showed a concentration increase from 663 to 1.610 (bichar-400) or 1.910 (bichar-500) mg/kg in GV and from 1.080 to 2.590 or $3.380 \mathrm{mg} / \mathrm{kg}$ in of $\mathrm{SFH}$. These results suggest that the biochar produced could be applied instead or conventional fertilizer [21] or perhaps blended with compost, in order to improve the growth of plants and increase the yield of crops [22]. The raw material and the related pyrolysed product are shown in Fig. 4.

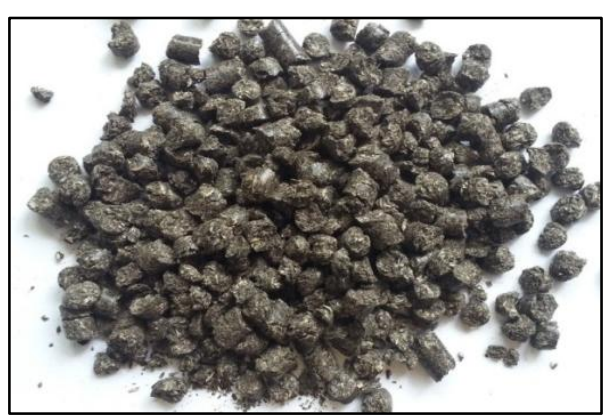

(a)

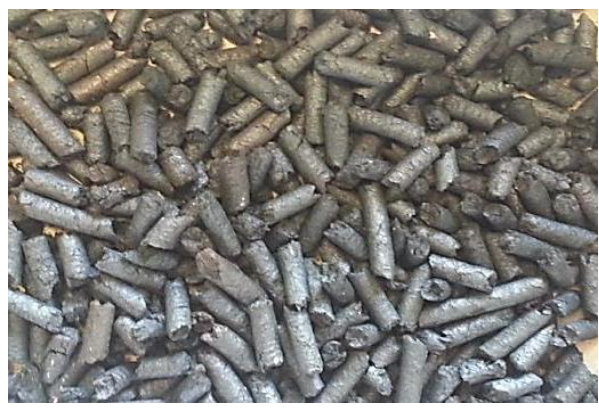

(c)

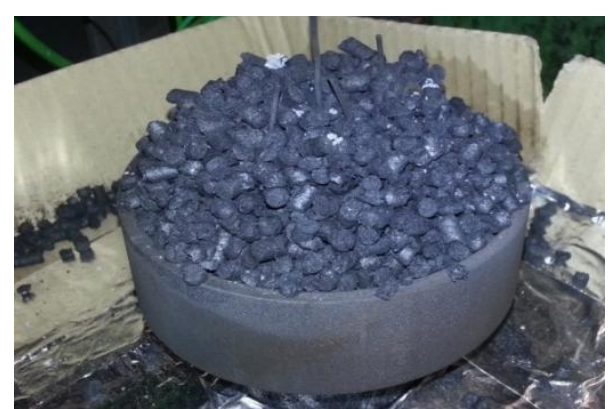

(b)

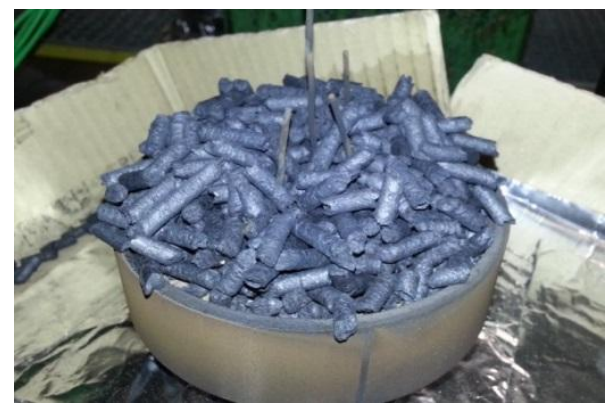

(d) 
Fig. 4. Pictures of feedstock investigated in the batch reactor: GV sample before (a) and after (b) and SFH before (c) and after (d) the test runs.

\section{Table 2}

Physicochemical properties of biochar.

\begin{tabular}{ccccccccccc}
\hline Feedstock & Temperature $\left({ }^{\circ} \mathrm{C}\right)$ & Duration $(\mathrm{s})$ & Yield $(\%)$ & Ash content & $\mathrm{C}(\%)$ & $\mathrm{H}(\%)$ & $\mathrm{O}(\%)$ & $\mathrm{N}(\%)$ & $\mathrm{S}(\%)$ \\
\hline GV & 400 & 3.600 & 40,36 & 7,05 & 69,68 & 4,34 & 25,22 & 0,76 & 0,04 \\
SFH & 400 & 3.600 & 36,17 & 7,53 & 70,26 & 4,47 & 23,98 & 1,29 & 0,19 \\
GV & 500 & 3.600 & 30,12 & 8,24 & 73,77 & 3,45 & 21,99 & 0,79 & 0,04 \\
SFH & 500 & 3.600 & 33,19 & 9,49 & 72,10 & 3,69 & 22,82 & 1,39 & 0,20 \\
\hline
\end{tabular}

\section{Table 3}

Chemical composition of biomass and corresponding biochar samples investigated ( $\mathrm{mg} / \mathrm{kg}$ dry basis); TIC - total inorganic carbon.

\begin{tabular}{llcccccc}
\hline Parameter & unit & \multicolumn{3}{c}{ SFH } & \multicolumn{3}{c}{ GV } \\
\hline $\mathrm{Cl}$ & & pellet & biochar-400 & biochar-500 & pellet & biochar-400 & biochar-500 \\
\cline { 2 - 8 } $\mathrm{Ca}$ & mg/kg d.b. & 577 & 699 & 1030 & 97 & 81 & 84 \\
$\mathrm{Si}$ & $\mathrm{mg} / \mathrm{kg}$ d.b. & 3960 & 9800 & 12500 & 6200 & 15200 & 17900 \\
$\mathrm{~K}$ & $\mathrm{mg} / \mathrm{kg}$ d.b. & 321 & 801 & 998 & 1740 & 4180 & 4780 \\
$\mathrm{Mg}$ & $\mathrm{mg} / \mathrm{kg}$ d.b. & 8070 & 20200 & 26500 & 3440 & 8590 & 10100 \\
$\mathrm{P}$ & $\mathrm{mg} / \mathrm{kg}$ d.b. & 2160 & 5500 & 6970 & 1020 & 2470 & 2840 \\
$\mathrm{Na}$ & $\mathrm{mg} / \mathrm{kg}$ d.b. & 1080 & 2590 & 3380 & 663 & 1610 & 1910 \\
$\mathrm{Zn}$ & $\mathrm{mg} / \mathrm{kg}$ d.b. & 11 & 25 & 38 & 63 & 157 & 181 \\
$\mathrm{~Pb}$ & $\mathrm{mg} / \mathrm{kg}$ d.b. & 18 & 44 & 61 & 26 & 67 & 77 \\
$\mathrm{Al}$ & $\mathrm{mg} / \mathrm{kg}$ d.b. & $<4.85$ & $<5.5$ & $<5.59$ & $<4.82$ & $<5.67$ & $<5.26$ \\
$\mathrm{Fe}$ & $\mathrm{mg} / \mathrm{kg}$ d.b. & 62 & 130 & 169 & 360 & 685 & 780 \\
$\mathrm{Mn}$ & $\mathrm{mg} / \mathrm{kg}$ d.b. & 312 & 260 & 326 & 346 & 761 & 896 \\
$\mathrm{Cu}$ & $\mathrm{mg} / \mathrm{kg}$ d.b. & 14 & 23 & 30 & 61 & 153 & 181 \\
$\mathrm{Cd}$ & $\mathrm{mg} / \mathrm{kg}$ d.b. & 11 & 26 & 33 & 20 & 49 & 56 \\
$\mathrm{TIC}$ & $\mathrm{mg} / \mathrm{kg}$ d.b. & $<0.291$ & $<0.33$ & $<0.335$ & $<0.289$ & $<0.34$ & $<0.315$
\end{tabular}

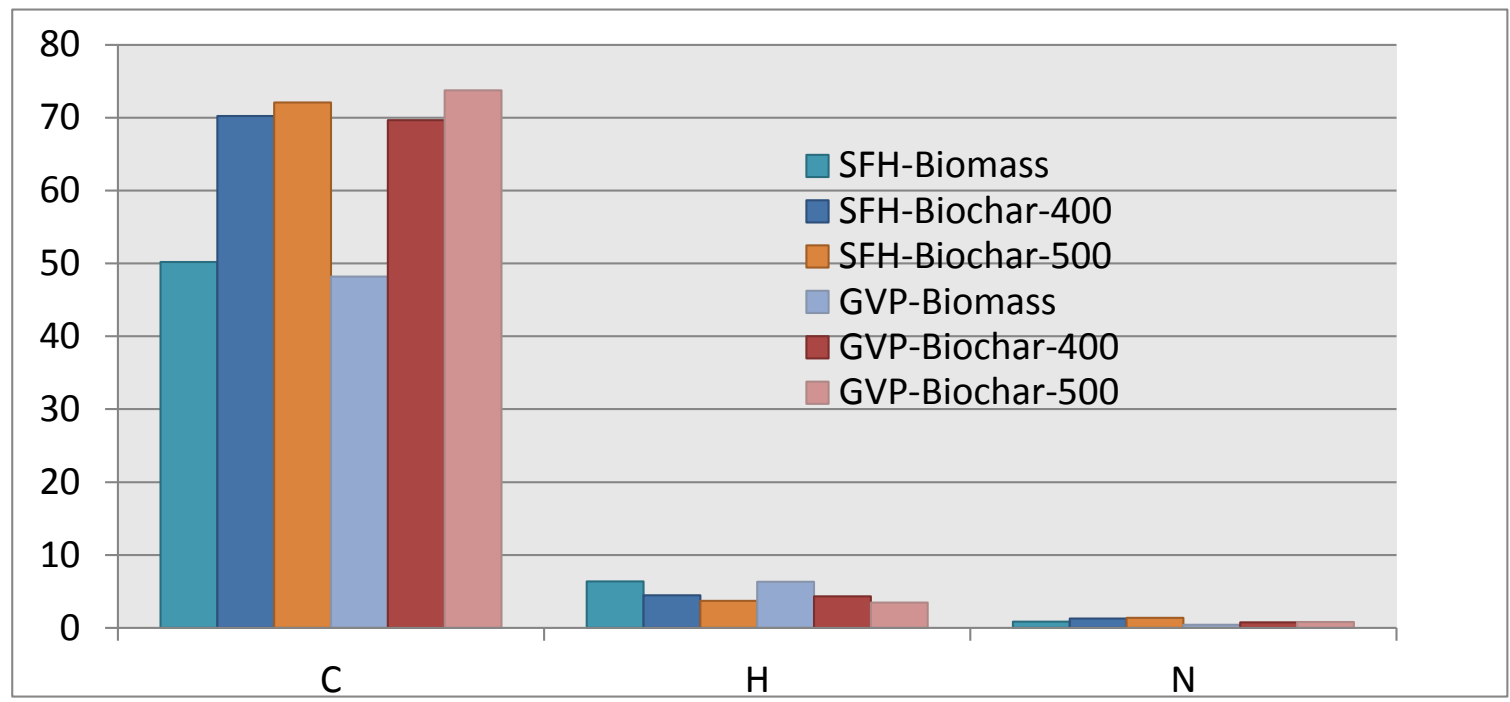

Fig. 5. $\mathrm{C}, \mathrm{H}, \mathrm{N}$ concentrations in wt $\%$ wet basis.. 


\subsection{Thermogravimetric analyses}

In Fig. $6(a, b, c, d)$ it can be seen that the rate of mass loss of GV and SFH increased with the increase of pyrolysis temperature. At the beginning (0-200 s) the main process is drying ,, indicated by a moderate mass loss, lower fuel bed temperatures (Fig. 7), and the release of water (Fig. 8). After about $200 \mathrm{~s}$, fuel decomposition starts, indicated by increasing $\mathrm{CO}_{2}$ concentrations in the flue gas (Fig. 8) [23]. The release of volatiles by gasification and parallel torrefaction of the biochar takes place until around $3.300 \mathrm{~s}$ in the test run duration. Graphs show that GV and SFH had similar mass reduction trends both at $400^{\circ} \mathrm{C}$ and $500^{\circ} \mathrm{C}$ because the biomass material was typically composed of cellulose, hemicellulose and lignin. Literature reports that hemicellulose begins to thermally decompose at $250^{\circ} \mathrm{C}$ and the process continues to $380^{\circ} \mathrm{C}$, cellulose degradation occurs between $300^{\circ} \mathrm{C}$ and $400^{\circ} \mathrm{C}$ and lignin degradation takes place at $200^{\circ} \mathrm{C}-$ $500^{\circ} \mathrm{C}$ [24]. Biochar mass followed a steady decreasing trend until about $2.000 \mathrm{~s}$ on each test run. At this time the thermocouple temperature stabilized (Fig. 5). As shown in Table 4, the sample masses used differed slightly for SFH because of bulk density deviations in the fuel itself. In general, the duration of the three main reaction phases, the release of volatiles followed by biochar torrefaction, generally increase with an increasing fuel sample mass.

Table 4

Characteristic data gained from the test runs with the biofuels.

\begin{tabular}{|c|c|c|c|c|c|}
\hline & Unit & $400^{\circ} \mathrm{C}$ & $500^{\circ} \mathrm{C}$ & $400{ }^{\circ} \mathrm{C}$ & $500{ }^{\circ} \mathrm{C}$ \\
\hline Sample mass & $g$ & 248,6 & 248,1 & 234,4 & 221,3 \\
\hline Biochar mass & g & 105,7 & 75 & 85,1 & 78,1 \\
\hline Maximum fluid temperature & ${ }^{\circ} \mathrm{C}$ & 439 & 533 & 458 & 534 \\
\hline Release of volatiles and charcoal gasification & s & 3.300 & 2.800 & 3.400 & 2.900 \\
\hline
\end{tabular}

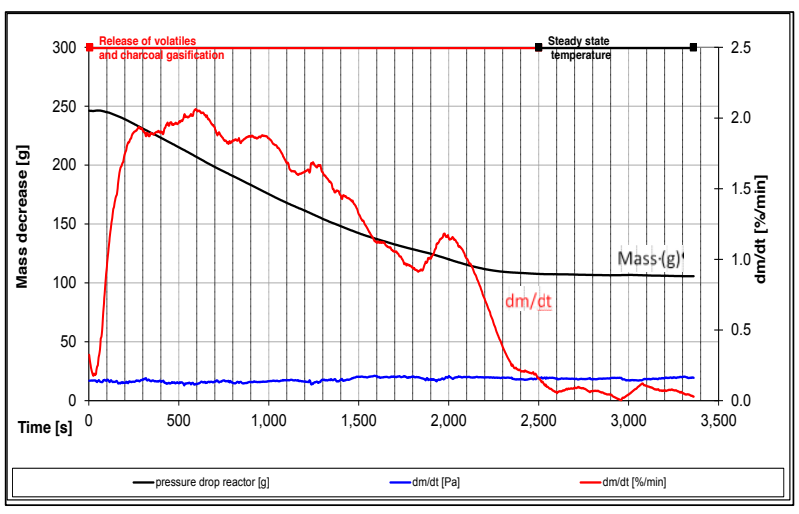

(a)

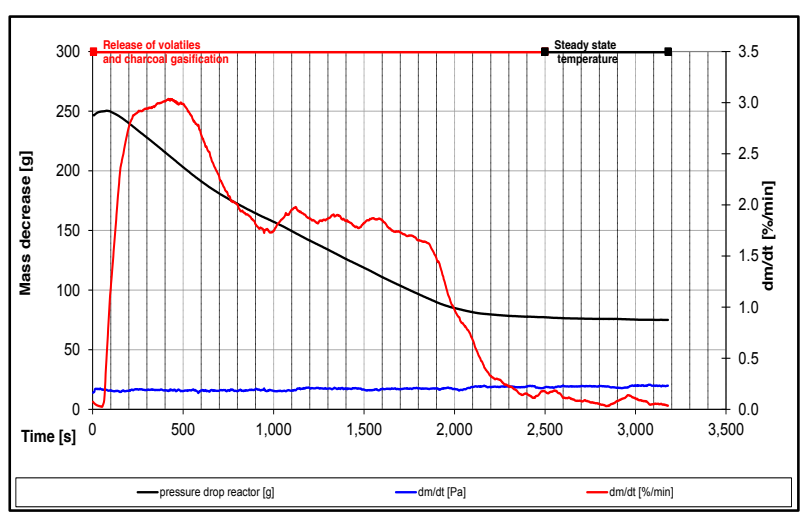

(b) 


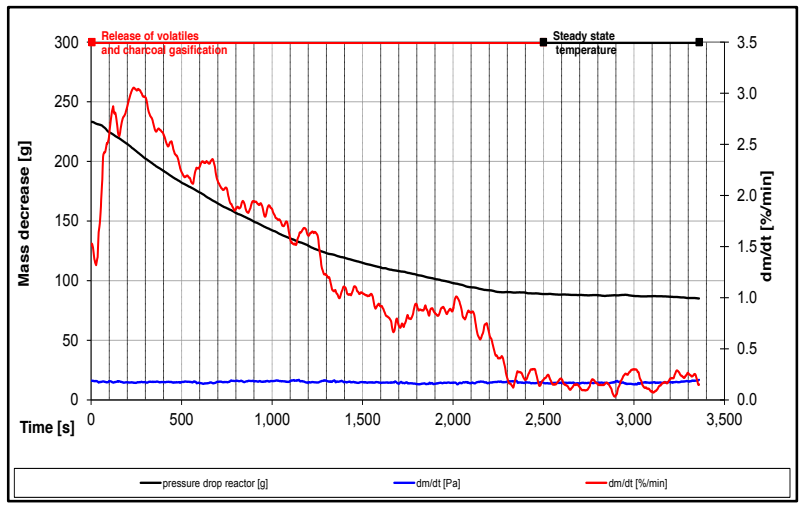

(c)

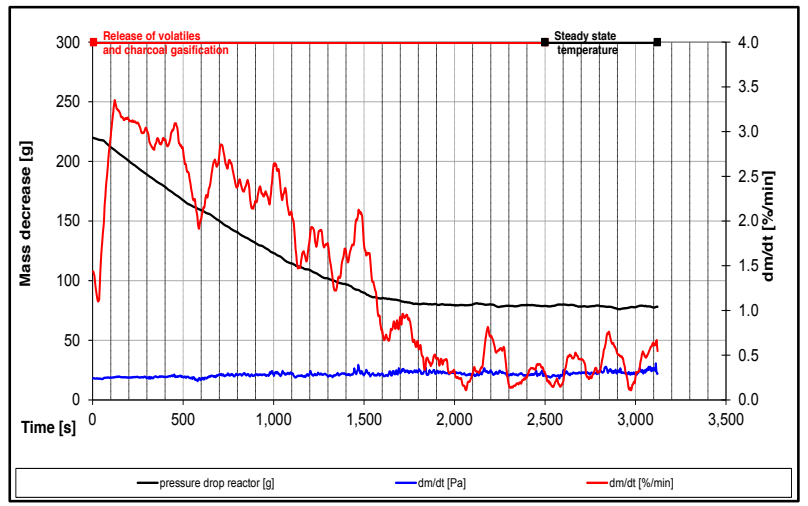

(d)

Fig. 6. Thermogravimetric analyses under different temperatures: (a) $\mathrm{GV}-400^{\circ} \mathrm{C}$, (b) $\mathrm{GV}-500^{\circ} \mathrm{C},(\mathrm{c}) \mathrm{SFH}-400^{\circ} \mathrm{C}$, (d) $\mathrm{SFH}-500^{\circ} \mathrm{C}$

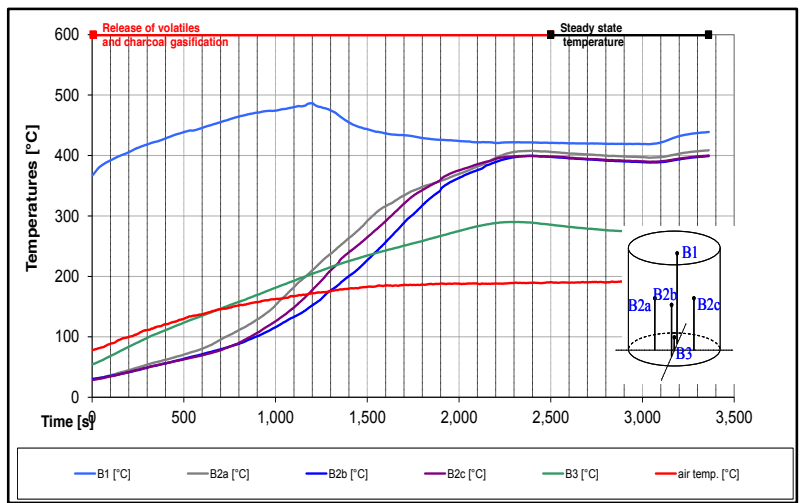

(a)

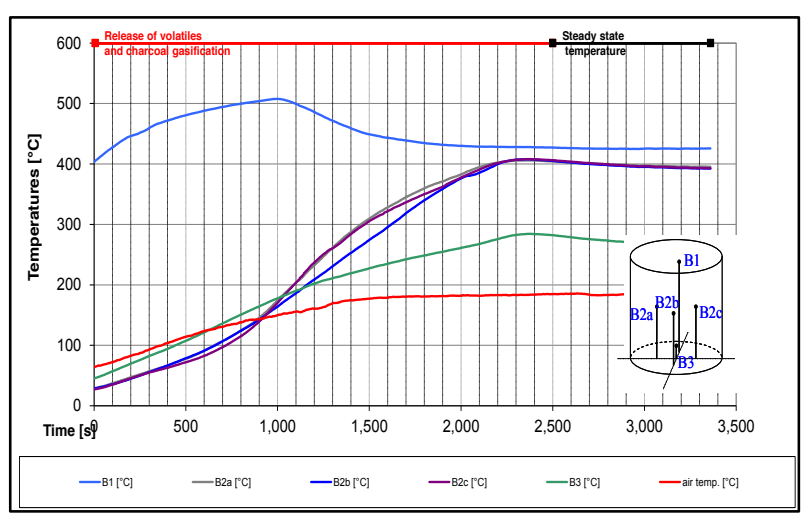

(c)

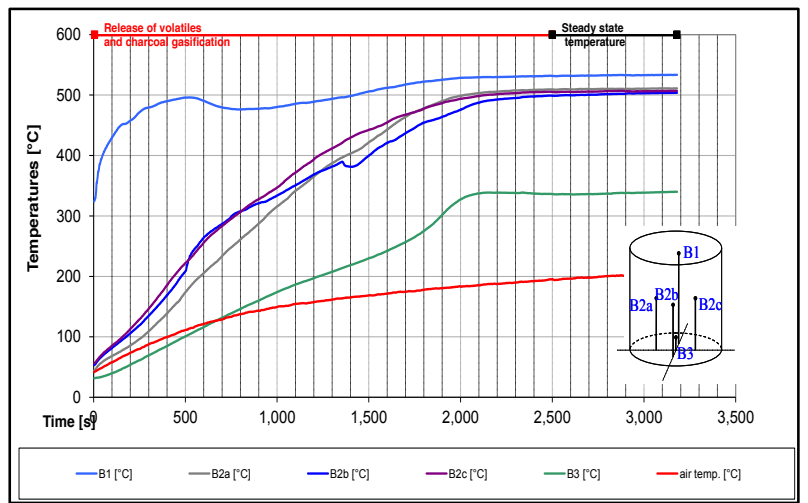

(b)

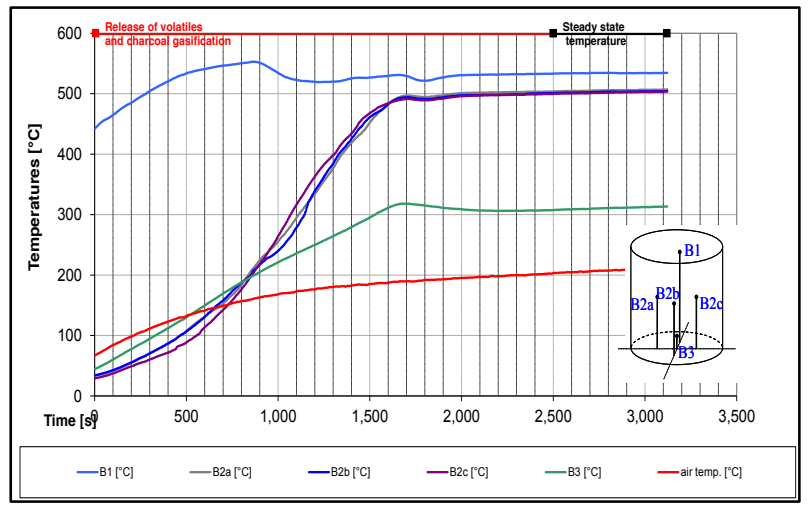

(d)

Fig. 7. Fuel bed and flue gas temperatures trend during (a) $\mathrm{GV}-400^{\circ} \mathrm{C}$, (b) $\mathrm{GV}-500^{\circ} \mathrm{C}$, (c) $\mathrm{SFH}-400^{\circ} \mathrm{C}$ and (d) SFH $500^{\circ} \mathrm{C}$ running tests

\subsection{Gas analysis}

Pyrolysis gas consisted mainly of $\mathrm{CO}_{2}, \mathrm{CO}, \mathrm{CH}_{4}$, with minor amounts of acetic acid, methanol, furfural, acetaldehyde, ethanol, and traces of $\mathrm{H}_{2}, \mathrm{SO}_{2}, \mathrm{HCl}$, ethene, acetylene, ethane, propane, formaldehyde, propene, carbonyl sulphide (COS), lactic acid, formic acid, propanal, hydroxymethylfural (HMF) (Table 5). Emissions of the main organic components were measured with Fourier Transform Infrared Spectroscopy (FTIR). Total gas composition integrated over the duration of the pyrolysis process for GV and SFH at each temperature is depicted in Table 4. A higher $\mathrm{CO}_{2}$ indicates the greater degradation of cellulosic and 
hemicellulosic contents, whereas $\mathrm{CH}_{4}$ and $\mathrm{CO}$ are a result of the secondary cracking of volatiles released from the process [23]. The variation in $\mathrm{CO}_{2}, \mathrm{CO}, \mathrm{CH}_{4}$ and $\mathrm{H}_{2}$ during the test runs (Fig. 8) and overall gaseous production (Table 5) agrees with the data given by other authors [25]. In Fig 8 it can be seen that the release of water takes place throughout the process, caused initially by evaporation of moisture contained in pellets, and subsequently by water produced by pyrolytic reactions in combination with other gases. Furfural can be used as a tracer for heavy condensable species. Other heavy condensable species cannot be detected with the employed setup.

\section{Table 5}

Pyrolysis gas compositions of the different test runs performed.

\begin{tabular}{|c|c|c|c|c|}
\hline \multirow[t]{2}{*}{ Parameter } & \multicolumn{2}{|c|}{ GV } & \multicolumn{2}{|c|}{$\mathrm{SFH}$} \\
\hline & $400^{\circ} \mathrm{C}$ & $500^{\circ} \mathrm{C}$ & $400^{\circ} \mathrm{C}$ & $500^{\circ} \mathrm{C}$ \\
\hline & \multicolumn{2}{|c|}{$\%$} & \multicolumn{2}{|c|}{$\%$} \\
\hline $\mathrm{H}_{2} \mathrm{O}$ & 47,42 & 44,23 & 38,29 & 36,57 \\
\hline $\mathrm{CO}_{2}$ & 25,13 & 26,21 & 31,8 & 31,39 \\
\hline $\mathrm{CO}$ & 9,02 & 11,61 & 7,25 & 10,55 \\
\hline $\mathrm{CH}_{4}$ & 2,97 & 4,59 & 4,43 & 7,14 \\
\hline Acetic acid & 5,92 & 3,92 & 6,15 & 3,79 \\
\hline Methanol & 2,05 & 1,68 & 1,67 & 1,46 \\
\hline Furfural & 2,79 & 2,27 & 3,24 & 1,87 \\
\hline Acetaldehyde & 1,38 & 1,56 & 1,79 & 1,86 \\
\hline Ethanol & 1,11 & 0,45 & 0,6 & 0,21 \\
\hline $\mathrm{H}_{2}$ & 0,13 & 0,28 & 0,09 & 0,39 \\
\hline $\mathrm{SO}_{2}$ & 0,15 & 0,01 & 0,09 & 0,01 \\
\hline $\mathrm{HCl}$ & - & - & 0,02 & 0,02 \\
\hline Ethene & 0,23 & 0,42 & 0,34 & 0,71 \\
\hline Acetylene & 0 & 0,02 & 1,79 & 0,01 \\
\hline Ethane & 0,07 & 0,13 & 0,13 & 0,22 \\
\hline Propane & 0,23 & 0,15 & 0,34 & 0,49 \\
\hline Formaldehyde & 0,11 & 0,1 & 0 & 0,02 \\
\hline Propene & 0,77 & 1,76 & 1,57 & 2,84 \\
\hline cos & - & - & 0,01 & 0,01 \\
\hline Lactic acid & 0,24 & 0,18 & 0,3 & 0,11 \\
\hline Formic acid & 0,03 & 0,04 & 0,01 & 0,11 \\
\hline Propanal & 0,13 & 0,05 & 0,01 & 0,02 \\
\hline HMF & 0,11 & 0,33 & 0,08 & 0,22 \\
\hline
\end{tabular}

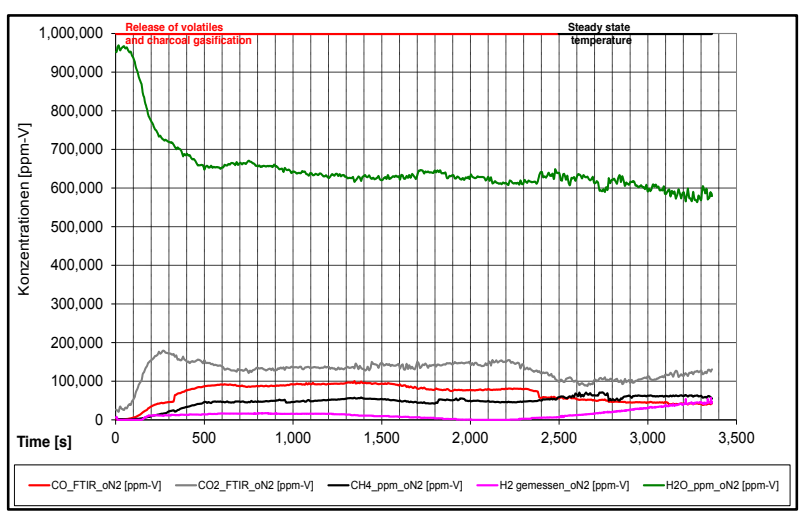

(a)

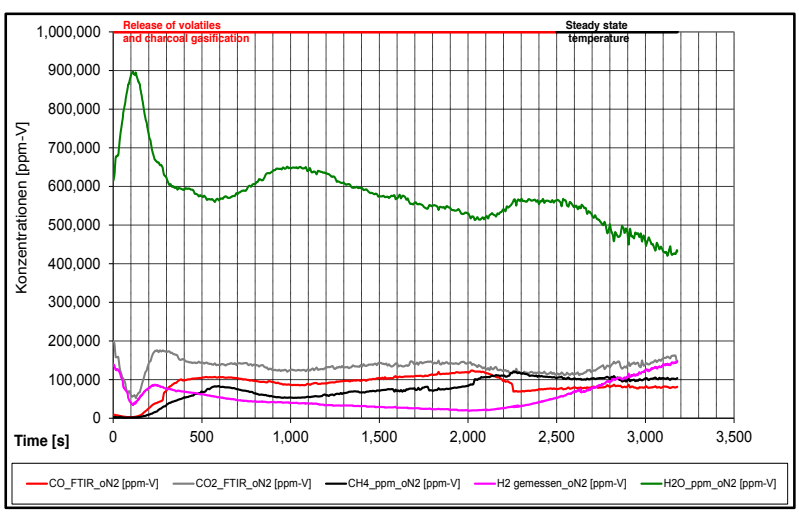

(b) 


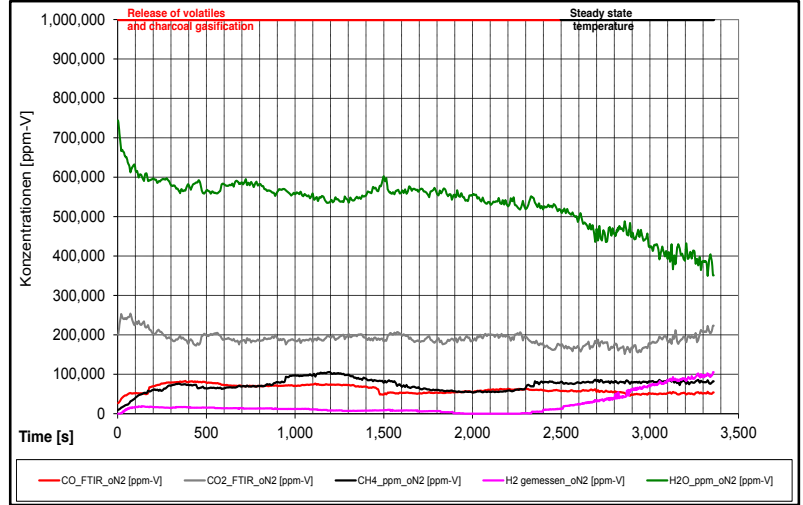

(c)

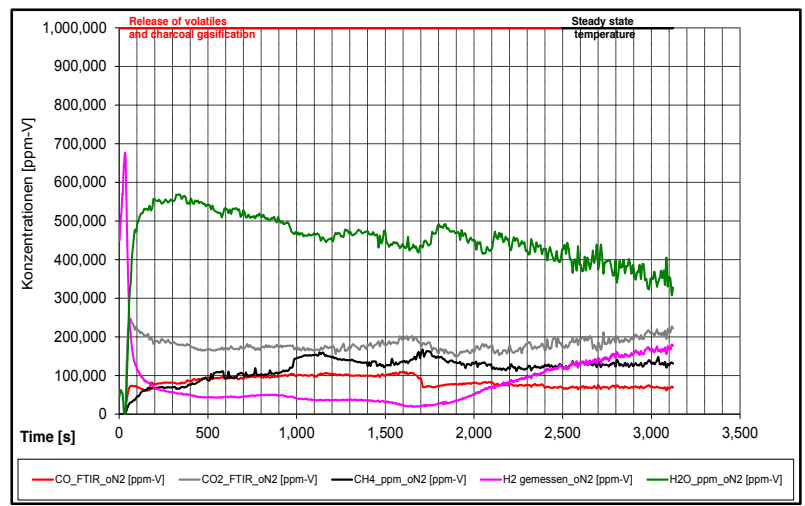

(d)

Fig. 8. Trends of the main gaseous components in relation to the temperature and duration of the test, (a) $\mathrm{GV}-400{ }^{\circ} \mathrm{C}$, (b) $\mathrm{GV}-500^{\circ} \mathrm{C}$, (c) $\mathrm{SFH}-400^{\circ} \mathrm{C}$, (d) $\mathrm{SFH}-500^{\circ} \mathrm{C}$

\section{Conclusions}

Our study was able to demonstrate an effective method to produce and characterise the biochar produced using pelletized biomass derived from any agricultural residue. The results of this experiment have shown that the torrefaction products obtained from pyrolysis of pelletized Austrian grape vine or sunflower husk residues is characterized by suitable chemical and physical characteristics for either an agronomic use as biochar or for an energetic use as charcoal. For the latter use it can be noted that the lower heating value and carbon content are similar to those of lignite, so this material could be used as a renewable alternative or substituted for non-renewable solid fuels in thermo-chemical processes or energy production. Regarding the potential use as fertilizer it is important to highlight that the biochars produced are expected to have a positive impact on soil nutrient characteristics due to the significant contents of phosphorous and potassium. Compared to the original agricultural residue the phosphorous concentration in the SFH-biochar-500 is increased by approx. $230 \%$ and in case of GVP-500 by $194 \%$. Similar increases were estimated in case of potassium. Thanks to the well-known porosity and high surface area properties of biochar its application could potentially act both as a kind of storage facility and source of these important elements, and to increase the soil water retention capacity [26], while reducing soil acidity due to its alkaline properties. With further study and the determination of additional characteristics, such as the effect of torrefacton on the availability of major nutrients and contaminants, water retention and plant growth inhibition, this approach could provide the necessary assurances for the recovery of various organic wastes and the inclusion of biochar in the list of common soil amendments for agricultural use as part of the EU's biobased Circular Economy [27].

\section{Acknowledgements}

This work was supported by BRISK (Biofuels Research Infrastructure for Sharing Knowledge) and in AgRes project by MIPAAF.

\section{References}

[1] Kwapinski W, Byrne CMP, Kryachko E, Wolfram P, Adley C, Leahy JJ, et al. Biochar from Biomass and Waste. Waste and Biomass Valorization 2010;1:177-89.

[2] Dersch G, Böhm K. Effects of agronomic practices on the soil carbon storage potential in arable farming in Austria. Nutrient Cycling in Agroecosystems 2001;60:49-55.

[3] Kahr H, Wimberger J, Schürz D, Jäger A. Evaluation of the Biomass Potential for the Production of Lignocellulosic Bioethanol from Various Agricultural Residues in Austria and Worldwide. Energy Procedia 2013;40:146-55. 
[4] Kung C-C, Kong F, Choi Y. Pyrolysis and biochar potential using crop residues and agricultural wastes in China. Ecological Indicators 2015;51:139-45.

[5] Luo L, Xu C, Chen Z, Zhang S. Properties of biomass-derived biochars: Combined effects of operating conditions and biomass types. Bioresource Technology 2015;192:83-9.

[6] Awad YM, Blagodatskaya E, Ok YS, Kuzyakov Y. Effects of polyacrylamide, biopolymer, and biochar on decomposition of soil organic matter and plant residues as determined by $14 \mathrm{C}$ and enzyme activities. European Journal of Soil Biology 2012;48:1-10.

[7] Bailey VL, Fansler SJ, Smith JL, Bolton H. Reconciling apparent variability in effects of biochar amendment on soil enzyme activities by assay optimization. Soil Biology and Biochemistry 2011;43:296-301.

[8] Rosas JG, Gómez N, Cara J, Ubalde J, Sort X, Sánchez ME. Assessment of sustainable biochar production for carbon abatement from vineyard residues. Journal of Analytical and Applied Pyrolysis 2015;113:239-47.

[9] Xue Y, Zhou S, Brown RC, Kelkar A, Bai X. Fast pyrolysis of biomass and waste plastic in a fluidized bed reactor. Fuel 2015;156:40-6.

[10] Usman AR a., Abduljabbar A, Vithanage M, Ok YS, Ahmad M, Ahmad M, et al. Biochar production from date palm waste: Charring temperature induced changes in composition and surface chemistry. Journal of Analytical and Applied Pyrolysis 2015;115:392-400.

[11] Bernardo M, Lapa N, Gonçalves M, Mendes B, Pinto F, Fonseca I, et al. Physico-chemical properties of chars obtained in the co-pyrolysis of waste mixtures. Journal of Hazardous Materials 2012;219220:196-202.

[12] Parmar A, Nema PK, Agarwal T. Biochar production from agro-food industry residues: A sustainable approach for soil and environmental management. Current Science 2014;107:1673-82.

[13] Al-Wabel MI, Al-Omran A, El-Naggar AH, Nadeem M, Usman AR a. Pyrolysis temperature induced changes in characteristics and chemical composition of biochar produced from conocarpus wastes. Bioresource Technology 2013;131:374-9.

[14] Yuan J-H, Xu R-K, Zhang $\mathrm{H}$. The forms of alkalis in the biochar produced from crop residues at different temperatures. Bioresource Technology 2011;102:3488-97.

[15] Ateş F, Miskolczi N, Borsodi N. Comparision of real waste (MSW and MPW) pyrolysis in batch reactor over different catalysts. Part I: Product yields, gas and pyrolysis oil properties. Bioresource Technology 2013;133:443-54.

[16] Bruun EW, Hauggaard-Nielsen H, Ibrahim N, Egsgaard H, Ambus P, Jensen P a., et al. Influence of fast pyrolysis temperature on biochar labile fraction and short-term carbon loss in a loamy soil. Biomass and Bioenergy 2011;35:1182-9.

[17] Onay O, Kockar OM. Slow, fast and flash pyrolysis of rapeseed. Renewable Energy 2003;28:241733.

[18] Zhang J, Liu J, Liu R. Effects of pyrolysis temperature and heating time on biochar obtained from the pyrolysis of straw and lignosulfonate. Bioresource Technology 2015;176:288-91.

[19] Mimmo T, Panzacchi P, Baratieri M, Davies C a., Tonon G. Effect of pyrolysis temperature on miscanthus (Miscanthus $\times$ giganteus) biochar physical, chemical and functional properties. Biomass and Bioenergy 2014;62:149-57. 
[20] Bergeron SP, Bradley RL, Munson A, Parsons W. Physico-chemical and functional characteristics of soil charcoal produced at five different temperatures. Soil Biology and Biochemistry 2013;58:140-6.

[21] McHenry MP. Agricultural bio-char production, renewable energy generation and farm carbon sequestration in Western Australia: Certainty, uncertainty and risk. Agriculture, Ecosystems \& Environment 2009;129:1-7.

[22] Agegnehu G, Bass AM, Nelson PN, Muirhead B, Wright G, Bird MI. Biochar and biochar-compost as soil amendments: Effects on peanut yield, soil properties and greenhouse gas emissions in tropical North Queensland, Australia. Agriculture, Ecosystems \& Environment 2015;213:72-85.

[23] Tinwala F, Mohanty P, Parmar S, Patel A, Pant KK. Intermediate pyrolysis of agro-industrial biomasses in bench-scale pyrolyser: Product yields and its characterization. Bioresource Technology 2015;188:258-64.

[24] Cabeza a., Sobrón F, Yedro FM, García-Serna J. Autocatalytic kinetic model for thermogravimetric analysis and composition estimation of biomass and polymeric fractions. Fuel 2015;148:212-25.

[25] Chen T, Liu R, Scott NR. Characterization of energy carriers obtained from the pyrolysis of white ash, switchgrass and corn stover - Biochar, syngas and bio-oil. Fuel Processing Technology 2016;142:124-34.

[26] Ennis C, Evans G, Islam M, Ralebitso-Senior T, Senior E. Biochar: Carbon sequestration, land remediation, and impacts on soil microbiology. Critical Reviews in Environmental Science and Technology 2012;22: 2311-64.

[27] Closing the loop - An EU action plan for the Circular Economy: European Commission 2015. 